\title{
Synthesis and characterization of poly(vinylchloride) type macrophotoinitiator comprising side-chain thioxanthone via click chemistry
}

\author{
H. Akat ${ }^{*}$ M. Ozkan \\ Ege University, Faculty of Science, Department of Chemistry, Bornova, Izmir, 35100, Turkey
}

Received 24 August 2010; accepted in revised form 7 November 2010

\begin{abstract}
Nowadays, the use of macromolecular photoinitiators provides for a good compatibility of the initiator in the formulation. Moreover, the migration of the initiator to the surface of the material is prevented, which results in low-odor and non-toxic coatings. In the present study, it has been demonstrated that polyvinylchloride macrophotoinitiator (PVC-TX) containing side chain thioxanthone $(2 \%)$ moieties were successfully prepared by 'click chemistry'. For this purpose, propargyl thioxanthone and polyvinylchloride with side chain azide moieties were reacted in $N, N$-dimethylformamide for 24 hours at $25^{\circ} \mathrm{C}$ in order to give corresponding macrophotoinitiator. The synthesized polymer was characterized by ${ }^{1} \mathrm{H}-\mathrm{NMR}$ (nuclear magnetic resonance), UV (ultraviolet) and fluorescence spectroscopies and water based gel permeation chromatography. Obtained macrophotoinitiator has similar absorption characteristics compared to parent thioxanthone. Its capabilities to act as initiator for the photopolymerization of methacrylic acid, methyl methacrylate, $N$-vinyl pyrrolidone and styrene in various solvents in the absence and presence of triethylamine media were also examined.
\end{abstract}

Keywords: polymer synthesis, molecular engineering, macrophotoinitiator, photopolymerization, click chemistry, thioxanthone

\section{Introduction}

During the last 25 years, there has been growing interest in UV-light initiated photo polymerization. Due to the advantages of macromolecules in comparison to low molecular weight analogues, significant developments are described in the synthesis of macrophotoinitiator. These developments can be arranged as energy saving, low volatility, very short cure time and higher activity [1-3].

Types of free radical photoinitiators can be divided into two classes, according to their radical generation mechanisms, namely cleavage-type (Type I) (benzoin ether, acylphosphine oxides) initiators undergo a very rapid bond cleavage after absorption of a photon on the other hand, type II initiators form relatively long-lived excited triplet states capable of undergoing hydrogen-abstraction or electron-transfer reactions with co-initiator molecules that are deliberately added to the monomer containing system [4]. Among these photoinitiators, thioxanthone (TX) derivatives have recently received interest because of their characteristic absorption of near UV range [5-12]. They have been introduced in processes such as printing inks, dental materials, surface coating, microelectronics, nanocoatings and photoresists [13-17].

Thioxanthone type photoinitiators that proceed via a hydrogen abstraction mechanism are exemplified by combination of TX and a hydrogen donor such as amine or alcohol. The radical derived from the donor can initiate the polymerization. For hydrogen abstraction type photoinitiators, activity of pho-

\footnotetext{
${ }^{*}$ Corresponding author, e-mail: hakan.akat@ege.edu.tr
}

(c) BME-PT 
toinitiating is designated by polymeric coil including substituent. Activity of polymeric photoinitiators is higher than lower molecular weight analogs because these have more effective excitement mechanism.

The 'click'-type reactions, mainly hold up as by Huisgen 1,3-dipolar azide-alkyne [18], [3+2], or have attracted much attention due to their important features including high yields, high tolerance of functional groups and selectivity [19]. Huisgen 1,3dipolar cycloaddition occurs between an alkyne and an organic azide to give triazole ring. The reactions can be performed under mild experimental conditions when catalyzed by copper (I). The development and the application of click chemistry in polymer and material science have recently been studied extensively [20-26].

Macrophotoinitiators including chromophoric groups either in the main chain or used as pendant groups can be prepared in two ways by click reaction: The first way; we can synthesize and polymerize monomers with photoreactive groups and the second way is to introduce photoreactive groups onto polymer chains.

Polyvinylchloride (PVC) is a low-cost and weatherresistant polymer. The irradiation behavior of PVC has been investigated in detail [27]. PVC is known to be sensitive to UV irradiation. Wypych et al. [28] used FT-IR of original and derivative products of photodegradation for identification of photoproducts and they have demonstrated that hydrogen abstraction leads to one of two possible radicals on PVC. In this connection, taking the advantage of this feature of PVC, we have synthesized a new macrophotoinitiator which the incorporation of TX moiety onto pendant position of PVC is accomplished by click reaction. It is demonstrated that macrophotoinitiator can initiate the polymerization of various monomers without the use of extra hydrogen donor such as amines.

\section{Experimental}

\subsection{Materials}

Styrene (S, 99\%, Product no: 240869, Aldrich, USA), $N$-vinyl2-pyrrolidone (NVP, 99\%, Product no: V3409. Aldrich, USA), methyl methacrylate (MMA, 99\%, Product no: W400201, Aldrich, USA) were distilled under reduced pressure before use. Tetrahydrofuran (THF, 99.8\%, Product no: MFCD00005356,
Acros Organics, Germany) was dried and distilled over benzophenone-Na. Other solvents were purified by conventional procedures. Triethylamine (TEA, 98\%, Product no: T0886, Sigma-Aldrich, USA), dichloromethane (99.9\%, Product no: 650463 , HPLC grade, Aldrich, USA) was distilled from calcium hydride $\left(\mathrm{CaH}_{2}\right)$. Dimethylformamide (DMF, +99\%, Product no: D4551, Aldrich, USA), dimethyl sulphoxide (DMSO, 99\%, Product no: D2650, Aldrich, USA), 1,1,1-tris-(hydroxymethyl)-propantriacrylate (TPTA, 95\%, Product no:16445, Alfa Aesar, Germany), acrylamide (AA, 99\%, Product no: 800830 , Merck, Germany), anhydrous magnesium sulfate (99\%, Product no: M7506, SigmaAldrich, USA), 2,2'-bipyridyl (99\%, Product no: 14453, Aldrich, USA), methylethyl ketone (99\%, Product no: 360473, Sigma-Aldrich, USA), cyclohexanone (CYCLOHEX 99\%, Product no: 398241, Sigma-Aldrich, USA), diethylether (98\%, Product no: 296082 , Sigma-Aldrich, USA), copper (I) bromide (97.0\%, Product no: MFCD00010969, Acros Organics, Germany), sodium azide $\left(\mathrm{NaN}_{3}, 99.5 \%\right.$, Product no: MFCD00003536, Acros Organics, Germany), methanol (99\%, Product no: MFCD00004595, Acros Organics, Germany), thiosalicylic acid (97\%, Product no: T33200 Sigma-Aldrich, USA), propargyl bromide ( 80 volume $\%$ in toluene, Product no: 81831, Fluka, USA) and phenol (99\%, Product no: P3653, Sigma-Aldrich, USA), were used as received. PVC (Mn: 41000, PDI: 2.17) was supplied by PETKIM (Product no: S23) co., Turkey.

\subsection{Instrumentation}

${ }^{1} \mathrm{H}-\mathrm{NMR}$ spectra were recorded on Varian AS-400 spectrometers in deuterated chloroform $\left(\mathrm{CDCl}_{3}\right)$ with $\mathrm{Si}\left(\mathrm{CH}_{3}\right)_{4}$ as internal standard, FT-IR spectra were recorded on a Perkin Elmer FTIR Spectrum One-B spectrometer. UV spectra were recorded on a Shimadzu UV-1601 spectrometer. Differential scanning calorimetry (DSC) was performed on a Perkin Elmer Diamond DSC. Molecular weights and polydispersities of the linear polymers were determined by gel-permeation chromatography (GPC) using a Viscotek GPCmax auto sampler system consisting of a pump, three ViscoGEL GPC columns (G2000HHR, G3000HHR and G4000HHR), a Viscotek UV detector and a Viscotek differential refractive index (RI) detector with THF as eluent at a flow rate of $1.0 \mathrm{ml} / \mathrm{min}$ at $30^{\circ} \mathrm{C}$. Both detectors 
were calibrated with polystyrene standards having narrow molecular weight distribution and so the quoted molecular weights of the polymers are expressed in terms of polystyrene equivalents. Data were analyzed using Viscotek OmniSEC Omni-01 software. For water soluble polymers, gel permeation chromatography measurements were performed at room temperature with a setup consisting of a pump (HP 1050), a refractive index detector (HP $1047 \mathrm{~A}$ ), and three high resolution Waters columns (AQ3.0, AQ4.0 and AQ5.0). The effective molecular weight ranges were 1000-60 000, 10 000400,000 and $50000-4000000$, respectively. Water was used as eluent at a flow rate of $0.5 \mathrm{ml} / \mathrm{min}$ at room temperature. Data analyses were performed with HP Chemstation Software. Elemental analysis of polymers was done with a LECO CHNS 932 elemental analyzer according to ASTM D5291-96.

Fluorescence measurements were carried out using a Perkin Elmer Model LS-50 spectrophotometer. All measurements were made at 90 - position and slit widths for excitation and emission were both kept at $15 \mathrm{~nm}$. Thermal gravimetric analysis (TGA) was performed on Perkin-Elmer Diamond TA/TGA with a heating rate of $10^{\circ} \mathrm{C}$ min under nitrogen flow.

\subsection{Photo-DSC}

Photo-DSC was conducted on a modified Perkin Elmer Diamond DSC equipped with a home-made aluminum cylinder. UV light $(320-500 \mathrm{~nm})$ was applied by a light guide (OmniCure Series 2000) with a light intensity of $18.40 \mathrm{~mW} / \mathrm{cm}^{2}$ measured by DeltaOhm model HD-9021 radiometer at the level of the surface of the cured samples ([PVC$\mathrm{TX}]=4.14 \cdot 10^{-4} \mathrm{~mol} \mathrm{l}^{-1}$; [TPTA $]=8 \mathrm{~mol} \mathrm{l}^{-1}$; [TEA $]=$ $3.9 \mathrm{~mol}^{-1}$; in DMSO). The mass of the samples was $8.0 \mathrm{mg}$, and the measurements were carried out in an isothermal mode at $30^{\circ} \mathrm{C}$ under a nitrogen flow of $20 \mathrm{ml} \cdot \mathrm{min}^{-1}$. The reaction heat liberated in the polymerization was directly proportional to the number of acrylate reacted in the system. By integrating the area under the exothermic peak, the conversion of the acrylate groups $(C)$ or the extent of the reaction was determined according to Equation (1):

$C=\frac{\Delta H_{\mathrm{t}}}{\Delta H_{0}^{\text {theory }}}$ where $\Delta H_{\mathrm{t}}$ is the reaction heat evolved at time $t$, and $\Delta H_{0}^{\text {theory }}$ is the theoretical heat for complete conversion. $\Delta H_{0}^{\text {theory }}=19.2 \mathrm{kcal} \cdot \mathrm{mol}^{-1}$ for an acrylate bond [29]. The rate of polymerization $\left(R_{\mathrm{p}}\right)$ is directly related to the heat flow $(\mathrm{d} H / \mathrm{d} t)$ by Equation (2):

$R_{\mathrm{p}}=\frac{\mathrm{d} C}{\mathrm{~d} t}=\frac{\frac{\mathrm{d} H}{\mathrm{~d} t}}{\Delta H_{0}^{\text {theory }}}$

\subsection{Synthesis of Azide Functional Polyvinylchloride (PVC-N3)}

PVC (1.000 g, $0.024 \mathrm{mmol}$ ) was dissolved in $N, N$ dimethylformamide $(20 \mathrm{ml}), \mathrm{NaN}_{3}(0.021 \mathrm{~g}$, $0.322 \mathrm{mmol}$; chlorine group's $2 \%$ ) was added. The resulting solution was allowed to stir at $25^{\circ} \mathrm{C}$ overnight and precipitated into methanol/water mixture ( $1 / 1$ by volume). Copolymer compositions of polymer were determined using Elemental analysis. The mole fractions of PVC (98\%) and PVC-TX (2\%) were calculated accordingly. ${ }^{1} \mathrm{H}-\mathrm{NMR}$ (DMSO): $\delta 4.5-4.35$ (b, 2H), 2.4-2.2 (b, 4H). FTIR $\% T\left(\mathrm{~cm}^{-1}\right): 2968-2910\left(-\mathrm{CH}_{2}\right), 2108\left(-\mathrm{N}_{3}\right), 834$ $(\mathrm{C}-\mathrm{Cl})$.

\subsection{Synthesis of 2-hydroxythioxanthone}

The synthesis of 2-hydroxythioxanthone (TX-OH) was conducted according to the literature [30]. The crude products were recrystallized from 1,4-dioxane/water (v/v 80:20).

\subsection{Synthesis of 2-(prop-2-yn-1-yloxy)-9H- thioxanthen-9-one}

A mixture of propargyl bromide $(0.165 \mathrm{~g}$, $1.300 \mathrm{mmol})$, potassium carbonate $(0.162 \mathrm{~g}$, $1.2 \mathrm{mmol})$, and TX-OH (0.228 g, $1.000 \mathrm{mmol})$ was stirred in deoxygenated and dry acetone $(5 \mathrm{ml})$ at $60^{\circ} \mathrm{C}$ for $4 \mathrm{~h}$. The reaction mixture was evaporated to dryness; the crude product was obtained as a yellow solid. Yield: 0.17 g. ${ }^{1} \mathrm{H}-\mathrm{NMR}$ (DMSO): $\delta$ ) 8.877.28 (b, 7H), 5.0-4.94 (s, 2H) 2.51 (s, 1H) FTIR $\% T\left(\mathrm{~cm}^{-1}\right): 3254(\mathrm{H}-\mathrm{C} \equiv \mathrm{C}-), 2131(-\mathrm{C} \equiv \mathrm{C}-), 1709$ $(\mathrm{C}=\mathrm{O}), 1024(\mathrm{C}-\mathrm{O})$,

\subsection{Synthesis of polyvinylchloride with thioxanthone side groups}

In a flask, above obtained PVC-N $3(0,410 \mathrm{~g}), 2-$ (prop-2-yn-1-yloxy)-9H-thioxanthen-9-one (TXPg) $(0.100 \mathrm{~g} 0.396 \mathrm{mmol})$, copper (I) bromide 
$(0,113 \mathrm{~g}, 0.792 \mathrm{mmol}), 2,2$ '-bipyridine $(0.247 \mathrm{~g}$, $1.584 \mathrm{mmol})$, and dry DMF (5 ml) were added. The flask was capped with a septum and purged with dry nitrogen for $10 \mathrm{~min}$. The mixture was stirred overnight at ambient temperature. After removing the catalyst by EDTA, functionalized polymer was precipitated in methanol $(200 \mathrm{ml})$, filtered and dried under vacuum. ${ }^{1} \mathrm{H}-\mathrm{NMR}$ (DMSO): $\delta$ ) 8.87-7.28 (b, $7 \mathrm{H}), 7.96(\mathrm{~s} 1 \mathrm{H}), 4.5-4.35$ (b, 2H), 4.96 (s, 2H) 2.4$2.2(\mathrm{~b}, 4 \mathrm{H})$ FTIR $\% T\left(\mathrm{~cm}^{-1}\right): 2968-2910\left(-\mathrm{CH}_{2}\right)$, $1712(\mathrm{C}=\mathrm{O}), 1091(\mathrm{C}-\mathrm{O})$,

\subsection{Photopolymerization}

Appropriate solutions of monomers $(10 \mathrm{mmol})$ in dimethylsuphoxide $(0,5 \mathrm{ml})$, sensitizer (PVC-TX; $4.16 \cdot 10^{-3} \mathrm{mmol}$ ) and triethyl amine (TEA; $1.6 \cdot 10^{-3} \mathrm{mmol}$ ) were added to Pyrex tubes and degassed with nitrogen before irradiation. The tubes were irradiated at room temperature in a merry-goround type photoreactor equipped with 15 Phillips lamps and emitting light nominally at $350 \mathrm{~nm}$. Light intensity was $1.04 \mathrm{~mW} / \mathrm{cm}^{2}$ as measured by DeltaOhm model HD-9021 radiometer. At the end of given time, polymers were poured into cold methanol, filtered, dried, and weighted. Conversions were determined gravimetrically.

\subsection{Photocuring}

Solution of PVC-TX $\left(4.14 \cdot 10^{-4} \mathrm{~mol} \cdot \mathrm{l}^{-1}\right)$ and PVC $4.14 \cdot 10^{-4} \mathrm{~mol} \cdot \mathrm{l}^{-1}$ ) in DMSO were added to Pyrex tubes the samples were irradiated for 2 hours from a photo reactor consisting of 15 Phillips lamps.

\section{Results and discussion}

In our study, we synthesized polyvinylchloride containing side-chain thioxanthone moieties (PVCTX) is based on 'click' chemistry strategy. Evidence for the occurrence of the click reactions was obtained from ${ }^{1} \mathrm{H}-\mathrm{NMR}$, UV and fluorescence spectroscopy.

We have first synthesized azide functionalized PVC $\left(\mathrm{PVC}-\mathrm{N}_{3}\right)$. So chlorine groups were converted to azide groups with the use of sodium azide. Approximately $2 \%$ of chlorine units were replaced with azides as estimated by elemental analysis $(38.93 \% \mathrm{C}$, $4.53 \% \mathrm{H}, 1.2 \% \mathrm{~N}, 55.34 \% \mathrm{Cl})$. From the ${ }^{1} \mathrm{H}-\mathrm{NMR}$ spectrum of the PVC- $\mathrm{N}_{3}$, the $\mathrm{N}_{3}-\mathrm{CH}-\left(\mathrm{CH}_{2}\right)-$ and $\mathrm{Cl}-\mathrm{CH}-\left(\mathrm{CH}_{2}\right)-$ protons are observed as multiple peaks at $4.5 \mathrm{ppm}$. Additionally, $\mathrm{N}_{3}-\mathrm{CH}-\left(\mathrm{CH}_{2}\right)-$ and

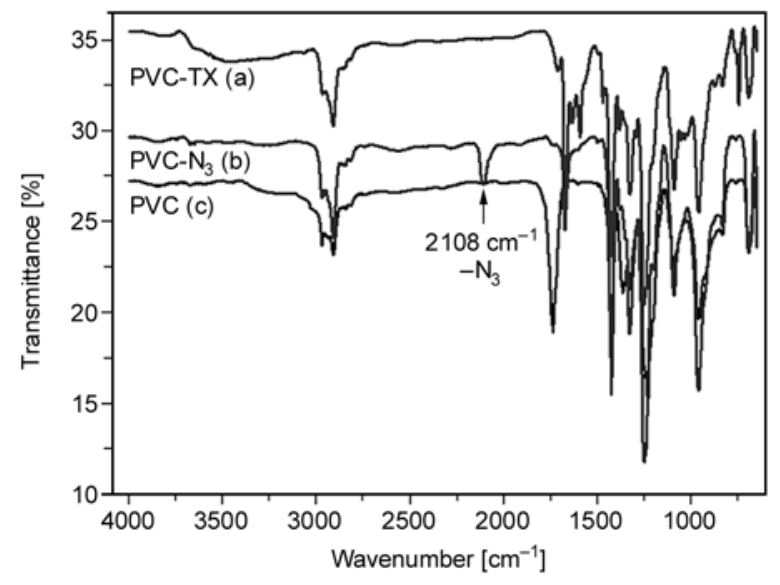

Figure 1. Infrared spectra of (a) PVC-TX, (b) PVC-N 3 and (c) PVC-TX

$\mathrm{Cl}-\mathrm{CH}-\left(\mathrm{CH}_{2}\right)-$ protons were detectable as broad signal between 2.21 and $2.42 \mathrm{ppm}$. The structure of PVC- $\mathrm{N}_{3}$ was further supported by the observationof the azide-stretching band at $2108 \mathrm{~cm}^{-1}$ in the FT-IR spectrum of PVC-N $\mathrm{N}_{3}$ presented in Figure 1.

The chemical structure of PVC-TX was confirmed by FT-IR, ${ }^{1} \mathrm{H}-\mathrm{NMR}$ and elemental analysis $(37,6 \% \mathrm{C}$, $4,14 \% \mathrm{H}, 1,22 \% \mathrm{~N}, 0,91 \% \mathrm{~S}, 0,89 \% \mathrm{O}, 55,24 \% \mathrm{Cl})$ The characteristic absorptions of TX-Pg appeared 3254, 2131, 1709, 1632, 1580, 1473,1436,1350, $1210,1024,825,752,687 \mathrm{~cm}^{-1}$ The Click functionality, propargyl group was evidenced by characteristic bands of $\mathrm{H}-\mathrm{C} \equiv \mathrm{C}-$ and $-\mathrm{C} \equiv \mathrm{C}$-appeared at 3250 and $2131 \mathrm{~cm}^{-1}$, respectively (Figure 2). The ${ }^{1} \mathrm{H}-\mathrm{NMR}$ spectrum of PVC-TX showed two new signals. One

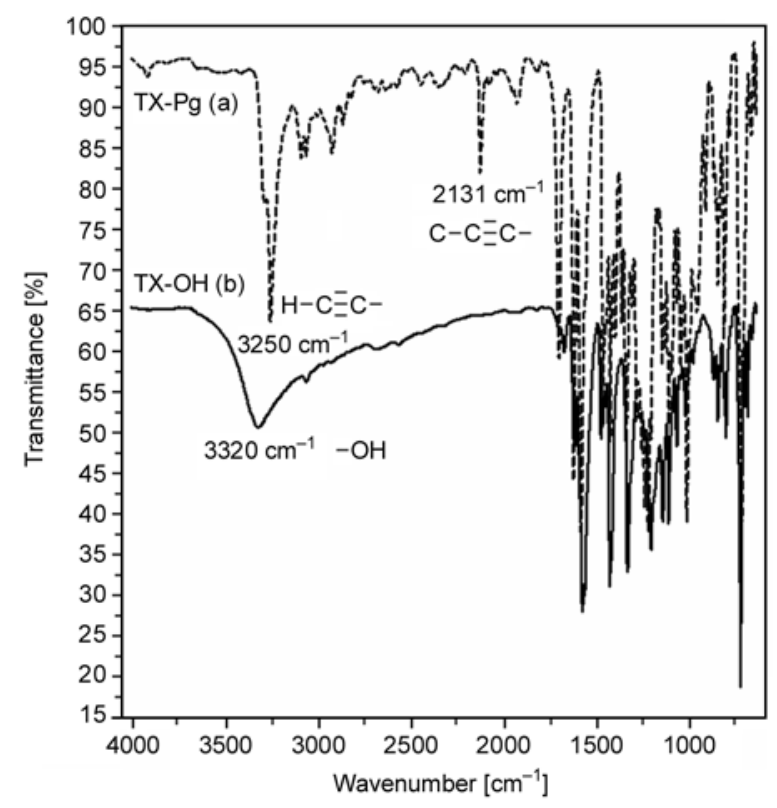

Figure 2. Infrared spectra of (a) TX-Pg and (b) TX-OH 
of them is a singlet $7.96 \mathrm{ppm}$ and second one is $4.96 \mathrm{ppm}$ which are assigned to $\mathrm{N}-\mathrm{CH}=\mathrm{C}-$ and $-\mathrm{CH}_{2}$ (propargyl) respectively. The peaks between 7.43 and $8.57 \mathrm{ppm}$, characteristic for aromatic protons of thioxanthone appeared in PVC-TX. The appearance of the peak belonging to $-\mathrm{CH}$ proton of the triazole ring at $7.96 \mathrm{ppm}$ is a typical indication for the successful completion of the click reaction. The FT-IR spectra (Figure 1 and 2) also confirm quantitative reaction, as the azide-stretching band at around $2108 \mathrm{~cm}^{-1}$ disappears completely and a new carbonyl and aromatic bands at $1709 \mathrm{~cm}^{-1}$ appears respectively.

Photophysical characteristics of the obtained PVCTX were investigated by UV and fluorescence spectroscopy. As can be seen from Figure 3, PVCTX, TX-OH and TX-Pg displays characteristic absorption of thioxanthone in $340-400 \mathrm{~nm}$ range while PVC- $\mathrm{N}_{3}$ did not. Compared with the maximum of absorption of TX-OH, the observed slight shift may be attributed to the addition of conjugated bounds in the molecules. The extinction coefficient of PVC-TX $(62300 \mathrm{l} /(\mathrm{mol} \cdot \mathrm{cm}))$ was much higher than that of TX-OH $(170001 /(\mathrm{mol} \cdot \mathrm{cm}))$ and TX-Pg $(20000 \mathrm{l} /(\mathrm{mol} \cdot \mathrm{cm}))$ at maximum wavelength $(395 \mathrm{~nm})$. Compared with the maximum of absorption of TX-OH, the observed slight shift may be attributed to the addition of conjugated bounds in the molecules. The extinction coefficient of PVCTX $(62300 \mathrm{l} /(\mathrm{mol} \cdot \mathrm{cm}))$ was much higher than that of TX-OH $(17000 \mathrm{l} /(\mathrm{mol} \cdot \mathrm{cm}))$ and TX-Pg $(20000 \mathrm{l} /(\mathrm{mol} \cdot \mathrm{cm}))$ at maximum wavelength $(395 \mathrm{~nm})$. Using these values we assumed that

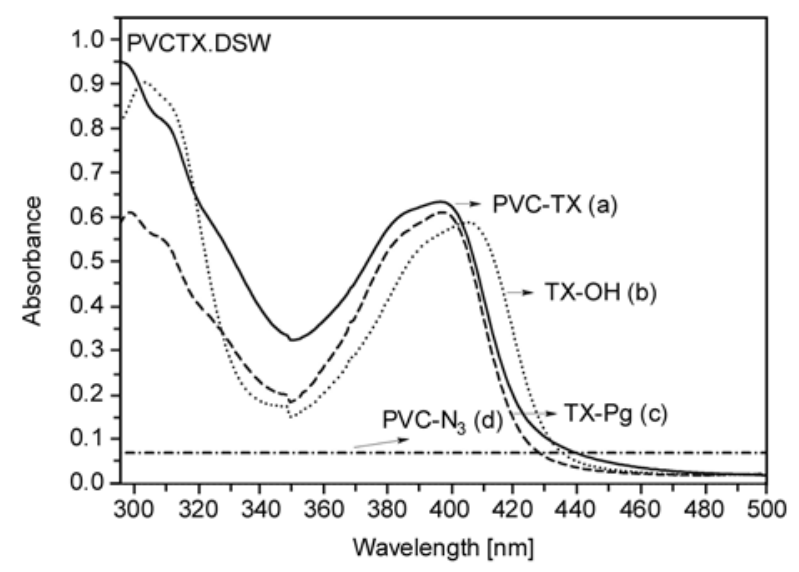

Figure 3. Absorption spectra of (a) PVC-TX (2\%), (b) PVC-N 3 , (c) TX-OH, and (d) TX-Pg in DMF. The concentrations are $1 \cdot 10^{-5} \mathrm{M}$ in terms of thioxanthone moieties.

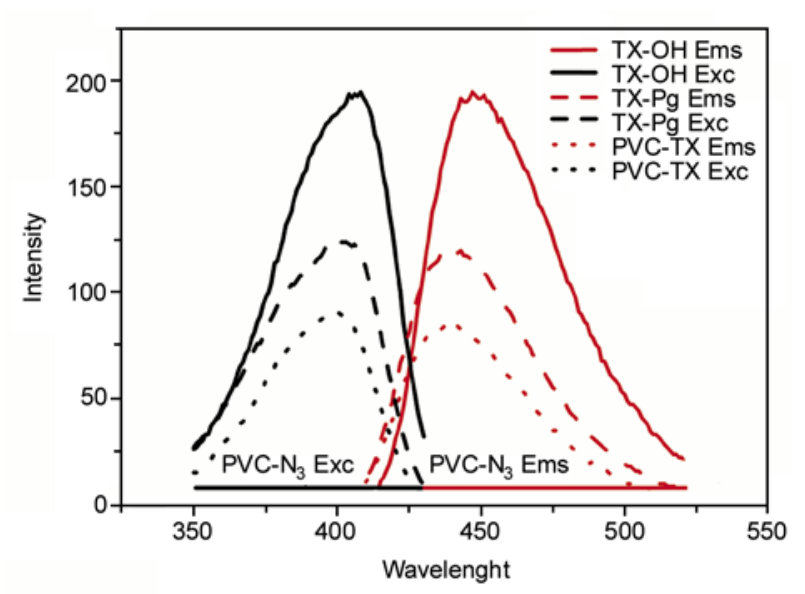

Figure 4. Emission spectra of PVC-TX (2\%), TX-Pg, PVC$\mathrm{N}_{3}$ and TX-OH in DMF; $\left(\lambda_{\text {exc }}\right) 380 \mathrm{~nm}$. The concentrations are $2 \cdot 10^{-5} \mathrm{M}$ in terms of thioxanthone moieties.

every PVC chain contains three TX molecules. This result was also consistent with FT-IR calculation.

Fluorescence spectra of PVC-TX may also provide further evidence for the efficiency of the modification process and information on the nature of the excited states involved. As can be seen from Figure 4, excitation and emission fluorescence spectra of TX-OH, TX-Pg and PVC-TX, which obtained click reaction in DMF, are quite similar. It's clear that when we look at the spectrum, we see a connection between absorption and emission. As expected, this relation between emission and absorption looks like a mirror image and it's so similar with pure thioxanthone. When there is side-chain thioxanthone bound polymer in the environment, the intensities are lower than usual. No excitation and emission fluorescence spectra are obtained for PVC- $\mathrm{N}_{3}$. It is also seen that variation of fluorescence is a bit different for TX-OH, TX-Pg and PVC-TX in spectrum. This could be due to several reasons. One of them is quenching which may be caused by a number of species in the environment. Secondly, it is considered that the addition of propargyl group can reduce the observed fluorescence intensity. Also, halogen groups in the polymer are thought to decrease the intensity of fluorescence. When we look at the structures, we can say that $\pi$ Orbital $\mathrm{C} \equiv \mathrm{C}$ moiety interacts with n-nonbonding orbitals on oxygen in TX. Because of this interaction fluorescence intensity of TX-Pg can be quenched efficiently atom containing compounds usually known as electron donors. With addition of the triazol 
group to PVC, electron distribution has been changed. Consequently, expected quantum yield is smaller than TX-OH.

Moreover, because of changing substituent, the molecule geometry in the excited state can be different from that of in the ground state. Relation between emission and absorption looks like a mirror image. This situation shows that the ground state geometry preserves itself in the excited state. With respect to absorbance peaks, fluorescence peaks shifted longer wavelength. This state is excepted result of the Stokes rule [31].

When we investigate the TX-structures, we can see that hydrogen groups substitute with propargyl and triazole groups. This can be attributed to electronic energy levels of the system have been varied in part.

Some polymeric systems can be used as bimolecular photoinitiators when they used with hydrogen donors. And these polymeric systems carry sidechain TX groups. And also, these hydrogen donors are so similar with low molecular weight TXs structures. PVC-TX was used as a macrophotoinitiator for the polymerization of various monomers in the presence of triethylamine (TEA) as hydrogen donor.

For comparison, we have done several experiments either in the presence or absence of TEA. As it can be seen Table 1 and 2, PVC-TX is also an efficient photoinitiator in the absence of a co-initiator but it should be pointed out that the presence of an amine such as TEA is important for more effective photoreduction and photopolymerization. Surprisingly, PVC-TX can self initiate the free radical polymerization of various monomers in the absence traditional hydrogen donors. We also checked the pho- toinitiating ability of neat PVC in the presence of TEA but this media did not start the photopolymerization. Consequently, it seems that PVC-TX has the ability to generate photoinitiating species itself without commercial amines.

There are so many solvents tested in our trials and dimetylsulphoxide (DMSO) is the most appropriate among these solvents for the photopolymerization (Table 2). Obviously, the situation seems to be complex and two effects are combined. First, PVC-TX dissolves in DMSO better than it dissolves in other solvents. Second, although radical polymerizations are not sensitive to the polarity of the solvent [3233], triplet-state lifetime of photoinitiators which involve electron transfer such as TX species, may depend on some polarity effects. The electron transfer mechanism of TX has been extensively investigated by spectroscopic and laser flash photolysis techniques in the literature [34-35].

We also used PVC-TX to test the polymerization ability of the other monomer such as styrene. When there is TEA in the environment, polymerization of styrene cannot initiated by PVC-TX. Although aromatic carbonyl/amine combinations represent an

Table 2. Effect of solvent on the photopolymerization of methyl methacrylate with PVC-TX at room temperature

\begin{tabular}{|l|c|c|c|}
\hline \multicolumn{1}{|c|}{ Solvent } & $\begin{array}{c}\text { Conversion } \\
{[\mathbf{\%}]}\end{array}$ & $\begin{array}{c}\mathbf{M}_{\mathbf{n}} \\
{[\mathbf{g} / \mathbf{m o l}]}\end{array}$ & $\mathbf{M}_{\mathbf{w}} / \mathbf{M}_{\mathbf{n}}$ \\
\hline DMSO & 49 & 19500 & 2.0 \\
\hline DMF & 31 & 19300 & 2.0 \\
\hline CYCLOHEX & 22 & 22200 & 2.3 \\
\hline MEK & 16 & 17380 & 2.2 \\
\hline THF & 27 & 19800 & 2.3 \\
\hline
\end{tabular}

$[\mathrm{MMA}]=10 \mathrm{~mol} \cdot \mathrm{l}^{-1} ;[\mathrm{PVC}-\mathrm{TX}]=4.16 \cdot 10^{-4} \mathrm{~mol} \cdot \mathrm{l}^{-1} ;[\mathrm{TEA}]=$ $16 \cdot 10^{-4} \mathrm{~mol} \cdot \mathrm{l}^{-1}$, irradiation time $=2 \mathrm{~h}$

Table 1. Photoinitiated free radical polymerization of various monomers with macrophotoinitiator in DMSO

\begin{tabular}{|c|c|c|c|c|c|}
\hline Monomer & $\begin{array}{l}\text { PVC-TX } \\
{\left[\mathrm{mol}^{-1} \mathrm{I}^{-1}\right]}\end{array}$ & $\begin{array}{c}\text { TEA } \\
{\left[\mathrm{mol}^{\left.-\mathrm{I}^{-1}\right]}\right]}\end{array}$ & $\begin{array}{c}\text { Conversion } \\
{[\%]}\end{array}$ & $\begin{array}{c}\text { Mn } \\
{[\mathrm{g} / \mathrm{mol}]}\end{array}$ & $\mathbf{M}_{\mathbf{w}} / \mathbf{M}_{\mathbf{r}}$ \\
\hline MA & $4.16 \cdot 10^{-4}$ & $16 \cdot 10^{-4}$ & 54 & $80877^{\mathrm{b}}$ & 2.16 \\
\hline MA & $4.16 \cdot 10^{-4}$ & - & 21 & $116950^{\mathrm{b}}$ & 1.90 \\
\hline MMA & $4.16 \cdot 10^{-4}$ & $16 \cdot 10^{-4}$ & 49 & 19500 & 1.98 \\
\hline MMA & $4.16 \cdot 10^{-4}$ & - & 18 & 125000 & 2.70 \\
\hline MMA & - & - & 4 & 296500 & 1.92 \\
\hline $\mathrm{MMA}^{\mathrm{a}}$ & $4.16 \cdot 10^{-4}$ & $16 \cdot 10^{-4}$ & No conversion & - & - \\
\hline NVP & $4.16 \cdot 10^{-4}$ & $16 \cdot 10^{-4}$ & 26 & $101200^{b}$ & 1.95 \\
\hline NVP & $4.16 \cdot 10^{-4}$ & - & 1.2 & $131500^{b}$ & 2.10 \\
\hline $\mathrm{S}$ & $4.16 \cdot 10^{-4}$ & $16 \cdot 10^{-4}$ & No conversion & - & - \\
\hline
\end{tabular}

${ }^{a}$ Neat PVC $\left(4.16 \cdot 10^{-4} \mathrm{~mol} / \mathrm{l}\right)$ was used instead of PVC-TX

${ }^{\mathrm{b}}$ calculated by water based GPC

irradiation time $=2 \mathrm{~h}$ 
effective photoinitiator system for the polymerization of (meth)acrylates, they seem to be less reactive toward styrene monomers because of the high quenching rate of the monomer and the low reactivity of R-amino radicals with styrene [36].

We also studied the efficiency of the PVC-TX in the photo-curing of formulations. And these formulations include multifunctional monomers (1,1,1-tris(hydroxymethyl)-propan-triacrylate, (TPTA). In Figure 5, we showed photo-DSC exotherms using PVC-TX, TEA TPTA under the polychromatic light. With using the knowledge derived from the Figure 5, we see that the Figure 6 displays a plot of the conversion vs. irradiation time. This 'conversion-time' kinetics curve indicates two stages; at first stage there is a rapid stage followed by a slow stage. At the second stage, the diffusion of the components becomes more difficult by the gelation and vitrification of the polymerization of tri-functional acrylate.

We have also investigated thermal stability of PVCTX by thermo gravimetric analyzer. In this connec-

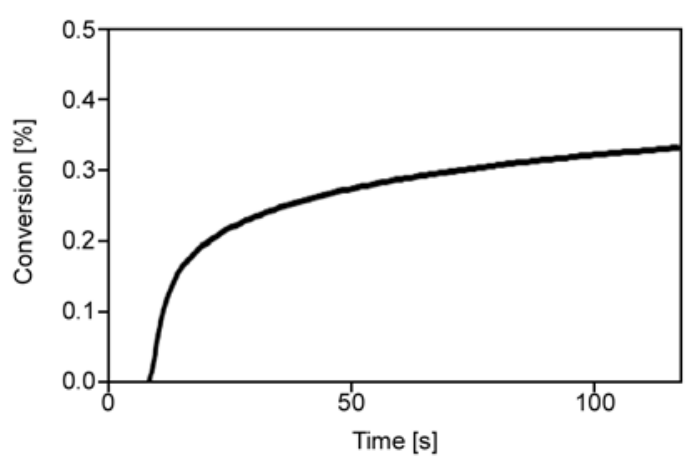

Figure 5. Conversion vs irradiation time for polymerization of TPTA in the presence of TEA and PVC-TX (2\%) macrophotoinitiator, cured at $30^{\circ} \mathrm{C}$ by UV light with an intensity of $18.40 \mathrm{~mW} / \mathrm{cm}^{2}$

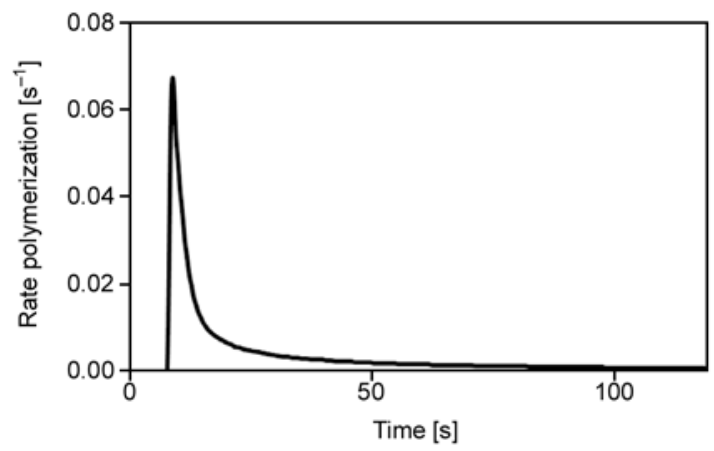

Figure 6. Photo-DSC profile for polymerization of TPTA in the presence of TEA and PVC-TX (2\%) macrophotoinitiator, cured at $30^{\circ} \mathrm{C}$ by UV light with an intensity of $18.40 \mathrm{~mW} / \mathrm{cm}^{2}$ tion, we irradiate (UV light) PVC and PVC-TX for 2 hours after then we plotted TGA curves of neat PVC, PVC-TX, photo-cured polyvinylchloride (PVC-PC) and photo-cured polyvinylchloride bearing thioxanthone (PVC-TX-PC). The first stage of PVC curve begins at $200^{\circ} \mathrm{C}\left(T_{0}\right)$ and ends at $375^{\circ} \mathrm{C}$ with a peak temperature at $300^{\circ} \mathrm{C}$. This corresponds to a weight loss of $63 \%$, which is attributed to the elimination of $\mathrm{HCl}$ molecules leaving behind longer polyene chains. The second stage of degradation begins at $375^{\circ} \mathrm{C}$ and ends at $500^{\circ} \mathrm{C}$ with a peak temperature of $465^{\circ} \mathrm{C}$. Thermal degradation of the polyene sequences occurs during this stage yielding volatile aromatic and aliphatic compounds by the intramolecular cyclisation of the conjugated sequences.

The TGA curves are presented in Figure 7. It should be noted that first step degradation temperatures for PVC, PVC-TX, PVC-PC and PVC-TX-PC are similar. Compared with polymers (PVC and PVC-TX), photocured polymers (PVC-PC and PVC-TX-PC) have more thermal stability due to crosslinking. According to data obtained from TGA studies, it is clear that the char yield of the photocured polymers is enhanced when compared with not photocured ones. Despite a high char yield of PVC-TX in comparison with other PVC, another noticeable feature is that the degradation of the photo-cured PVC-TX seems to be similar to the degradation profile of PVC, PVC-PC and PVC-TX. Also compared with PVC, PVC-TX is less degradable due to three reasons. Firstly, PVC-TX has TX moieties, which is higher molecular weight instead of $2 \% \mathrm{Cl}$. Secondly, aromatic groups are situated in the structure. Finally, PVC-TX is crosslinked with photocuring.

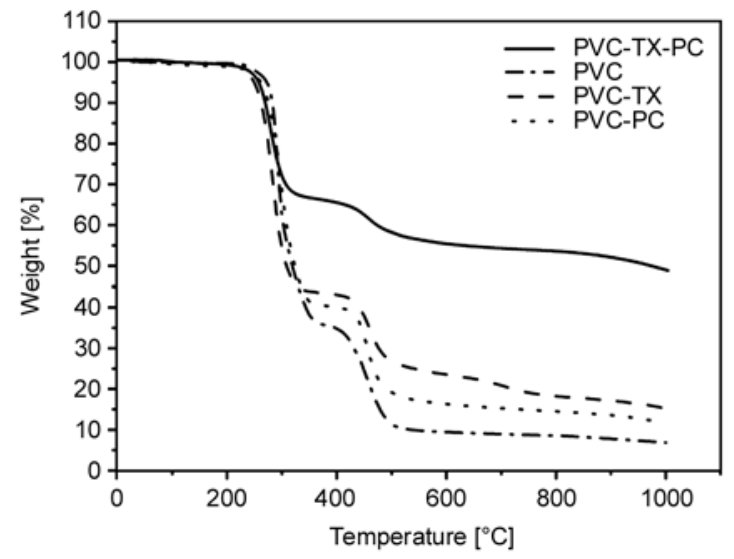

Figure 7. TGA curves of PVC-TX and PVC after and before uv curing 
This state has been reflected all stages of thermal degradation.

\section{Conclusions}

In conclusion, we have successfully synthesized $[3+2]$ click reactions for the synthesis of PVC bearing side-chain TX photoactive groups. One of the consequences of the synthesis macrophotoinitatior is that such modification causes a dramatic change in PVC chemistry. The obtained polymeric photoinitiators were shown to efficiently initiate the free radical polymerization of mono- and multifunctional monomers via hydrogen abstraction type mechanism without the use of extra hydrogen donor such as amines. Secondly, the capability of PVCTX acts, as type II photoinitiator in the absence of hydrogen donor is interesting and worthwhile for the industrial applications.

\section{Acknowledgements}

The authors thank Prof. Yusuf Yagci for photo DSC experiments.

\section{References}

[1] Corrales T., Catalina F., Peinado C., Allen N. S.: Free radical macrophotoinitiators: An overview on recent advances. Journal of Photochemistry and Photobiology A: Chemistry, 159, 103-114 (2003).

DOI: 10.1016/S1010-6030(03)00175-8

[2] Jiang X., Yin J.: Dendritic macrophotoinitiator containing thioxanthone and coinitiator amine. Macromolecules, 37, 7850-7853 (2004).

DOI: $10.1021 / \mathrm{ma} 0488360$

[3] Jiang X., Xu H., Yin J.: Copolymeric dendritic macrophotoinitiators. Polymer, 46, 11079-11084 (2005). DOI: 10.1016/j.polymer.2005.09.014

[4] Aydin M., Arsu N., Yagci Y., Jockusch S., Turro N. J.: Mechanistic study of photoinitiated free radical polymerization using thioxanthone thioacetic acid as onecomponent type II photoinitiator. Macromolecules, 38, 4133-4138 (2005). DOI: $10.1021 / \mathrm{ma} 047560 \mathrm{t}$

[5] Jiang X., Yin J.: Copolymeric photoinitiators containing in-chain thioxanthone and coinitiator amine for photopolymerization. Journal of Applied Polymer Science, 94, 2395-2400 (2004).

DOI: $10.1002 / a p p .21178$

[6] Jiang X., Luo J., Yin J.: A novel amphipathic polymeric thioxanthone photoinitiator. Polymer, 50, 37-41 (2009).

DOI: $10.1016 /$ j.polymer.2008.10.038
[7] Gacal B., Akat H., Balta D. K., Arsu N., Yagci Y.: Synthesis and characterization of polymeric thioxanthone photoinitatiors via double click reactions. Macromolecules, 41, 2401-2405 (2008).

DOI: $10.1021 / \mathrm{ma} 702502 \mathrm{~h}$

[8] Wen Y. N., Jiang X. S., Liu R., Yin J.: Amphipathic hyperbranched polymeric thioxanthone photoinitiators (ahptxs): Synthesis, characterization and photoinitiated polymerization. Polymer, 50, 3917-3923 (2009). DOI: $10.1016 /$ j.polymer.2009.06.065

[9] Yagcı Y., Jockusch S., Turro N. J.: Photoinitiated polymerization: Advances, challenges, and opportunities. Macromolecules, 43, 6245-6260 (2010).

DOI: $10.1021 / \mathrm{ma1007545}$

[10] Wen Y., Jiang X., Yin J.: Polymeric Michler's ketone photoinitiator containing coinitiator amine. Polymer Engineering and Science, 49, 1608-1615 (2009). DOI: $10.1002 /$ pen.21335

[11] Temel G., Arsu N., Yagci Y.: Polymeric side chain thioxanthone photoinitiator for free radical polymerization. Polymer Bulletin, 57, 51-56 (2006).

DOI: $10.1007 / \mathrm{s} 00289-006-0538-\mathrm{y}$

[12] Temel G., Arsu N.: One-pot synthesis of water-soluble polymeric photoinitiator via thioxanthonation and sulfonation process. Journal of Photochemistry and Photobiology A: Chemistry, 202, 63-66 (2009).

DOI: $10.1016 /$ j.jphotochem.2008.11.012

[13] Nese A., Sen S., Tasdelen M. A., Nugay N., Yagci Y.: Clay-PMMA nanocomposites by photoinitiated radical polymerization using intercalated phenacyl pyridinium salt initiators. Macromolecular Chemistry and Physics, 207, 820-826 (2006).

DOI: $\underline{10.1002 / \mathrm{macp} .200500511}$

[14] Oral A., Tasdelen M. A., Demirel A. L., Yagci Y.: Poly(cyclohexene oxide)/clay nanocomposites by photoinitiated cationic polymerization via activated monomer mechanism. Journal of Polymer Science Part A: Polymer Chemistry, 47, 5328-5335 (2009).

DOI: $10.1002 /$ pola.23581

[15] Tasdelen M. A., Kreutzer J., Yagci Y.: In situ synthesis of polymer/clay nanocomposites by living and controlled/living polymerization. Macromolecular Chemistry and Physics, 211, 279-285 (2010).

DOI: $10.1002 / \mathrm{macp} .200900590$

[16] Tasdelen M. A., Kumbaraci V., Jockusch S., Turro N. J., Talinli N., Yagci Y.: Photoacid generation by stepwise two-photon absorption: Photoinitiated cationic polymerization of cyclohexene oxide by using benzodioxinone in the presence of iodonium salt. Macromolecules, 41, 295-297 (2008).

DOI: $10.1021 / \operatorname{ma} 7023649$

[17] Roffey C.: Photogeneration of reactive species for UVcuring. Wiley, Sussex (1997).

[18] Padwa A.: 1,3-dipolar cycloaddition chemistry. Wiley, New York (1984). 
[19] Rostovtsev V. V., Green G., Fokin V. V., Sharpless K. B.: A stepwise huisgen cycloaddition process: copper(I)catalyzed regioselective 'ligation' of azides and terminal alkynes. Angewandte Chemie International Edition, 41, 2596-2599 (2002).

DOI: $10.1002 / 1521-3773(20020715) 41: 14<2596::$ AIDANIE2596>3.0.CO;2-4

[20] Tasdelen M. A., Van Camp W., Goethals E., Dubois P., Du Prez F., Yagci Y.: Polytetrahydrofuran/clay nanocomposites by in situ polymerization and 'click' chemistry processes. Macromolecules, 41, 6035-6040 (2008). DOI: $10.1021 / \mathrm{ma} 801149 \mathrm{x}$

[21] Oral A., Tasdelen M. A., Demirel A. L., Yagci Y.: Poly(methyl methacrylate)/clay nanocomposites by photoinitiated free radical polymerization using intercalated monomer. Polymer, 50, 3905-3910 (2009). DOI: $10.1016 /$ j.polymer.2009.06.020

[22] Opsteen J. A., van Hest J. C. M.: Modular synthesis of block copolymers via cycloaddition of terminal azide and alkyne functionalized polymers. Chemical Communications, 1, 57-59 (2005).

DOI: $10.1039 / \mathrm{b} 412930 \mathrm{j}$

[23] Lutz J-F.: 1,3-dipolar cycloadditions of azides and alkynes: a universal ligation tool in polymer and materials science. Angewandte Chemie International Edition, 46, 1018-1025 (2007).

DOI: 10.1002/anie.200604050

[24] Binder W. H., Sachsenhofer R.: 'Click' chemistry in polymer and materials science. Macromolecular Rapid Communications, 28, 15-54 (2007).

DOI: $10.1002 /$ marc.200600625

[25] Ergin M., Kiskan B., Gacal B., Yagci Y.: Thermally curable polystyrene via click chemistry. Macromolecules, 40, 4724-4727 (2007). DOI: $10.1021 / \mathrm{ma} 070549 \mathrm{j}$

[26] Fournier D., Hoogenboom R., Schubert U. S.: Clicking polymers: A straightforward approach to novel macromolecular architectures. Chemical Society Reviews, 36, 1369-1380 (2007).

DOI: $10.1039 / \mathrm{b} 700809 \mathrm{k}$
[27] Bowmer T. N., Hellman M. Y., Vroom W. I.: Radiation crosslinking of poly(vinyl-chloride) with trimethylolpropanetrimethacrylate. 2. Dependence on radiationdose and blend composition. Journal of Applied Polymer Science, 28, 2082-2092 (1983).

DOI: $10.1002 / a p p .1983 .070280620$

[28] Wypych G.: PVC degradation and stabilization, ChemTec Publishing, Ontario (2008).

[29] Brandrup J., Immergut E. H.: Polymer handbook, Wiley, New York (1975).

[30] Catalina F., Tercero J. M., Peinado C., Saster R., Mateo J. L.: Photochemistry and photopolymerization study on 2-acetoxy and methyl-2-acetoxy derivatives of thioxanthone as photoinitiators. Journal of Photochemistry and Photobiology A: Chemistry, 50, 249258 (1989).

DOI: 10.1016/1010-6030(89)85019-1

[31] Lakowicz J. R.: Princples of fluorescence spectroscopy. Kluwer, New York (1999).

[32] Binder W. H., Kluger C.: Combining ring-opening metathesis polymerization (romp) with sharpless-type 'click' reactions: An easy method for the preparation of side chain functionalized poly(oxynorbornenes). Macromolecules, 37, 9321-9330 (2004).

DOI: $10.1021 / \mathrm{ma} 0480087$

[33] Allen N. S., Catalina F., Green P. N., Green W. A.: Photochemistry of thioxanthones-IV. Spectroscopic and flash photolysis study on novel $n$-propoxy and methyl, n-propoxy derivatives. European Polymer Journal, 22, 793-799 (1986).

DOI: 10.1016/0014-3057(86)90018-2

[34] Amirzadeh G., Schnabel W.: On the photoinitiation of free radical polymerization-laser flash photolysis investigations on thioxanthone derivatives. Macromolecular Chemistry and Physics, 182, 2821-2825 (1981). DOI: $10.1002 / \mathrm{macp} .1981 .021821027$

[35] Yates S. F., Schuster G. B.: Photoreduction of triplet thioxanthone by amines- Charge-transfer generates radicals that initiate polymerization of olefins. Journal of Organic Chemistry, 49, 3349-3356 (1984). DOI: 10.1021/jo00192a019

[36] Pappas S. P.: Photoinitiated radical polymerization. Journal of Radiation Curing, 14, 6-10 (1987). 